\title{
Direito de fuga
}

\author{
Marcelo Naputano \\ MEZZADRA, Sandro. Direito de Fuga. \\ Edições Unipop, 2012. 176 p.
}

Os movimentos migratórios sempre fizeram parte da história da humanidade. Desde os primórdios, com aparecimento do Homo sapiens, temos a coexistência do Homo migrans e do Homo viator, demonstrando que as migraçóes e os deslocamentos sempre foram parte constitutiva da condição humana, tal como o nascimento, a procriaçáo, a doença e a morte. Aliás, o próprio nascimento e o restante da vida podem ser considerados como uma grande viagem ou como uma migração no tempo e no espaço (JUSTO, 2012).

Contudo, na atualidade, o mundo nunca teve tanta gente morando fora do lugar de origem. Quantificando estatisticamente, para melhor visualização da expressão desses movimentos migratórios, segundo as Naçóes Unidas os migrantes internacionais em 2015 eram cerca 244 milhóes de pessoas que, se comparadas ao ano de 2000 , tiveram um incremento de $41,1 \%$. Número este que fica ainda mais expressivo se somado aos migrantes internos que em 2009 foram estimados em 740 milhóes também pelas Naçóes Unidas. O que emerge da pesquisa Trends in internacional migrant stock: the 2015 revision (UNITED NATIONS, 2015) é o fato de que as migraçóes continuarão a crescer em todo o mundo sobretudo entre países limítrofes ou, pelo menos, naqueles pertencentes ao mesmo continente.

O Brasil contemporâneo não é uma exceção nessa conjuntura mundial. Em tempos remotos, por motivos coloniais, e em tempos mais próximos, por motivos das crises político-sociais europeias. Principalmente

\footnotetext{
Atualmente é pesquisador de pós-doutorado pela Universidade Estadual Paulista/UNESP. Doutor, Mestre e Psicólogo pela UNESP com Sanduiche na Università di Bologna/UNIBO na Itália. Especializações na Itália em Educação Intercultural pela Università RomaTre/ROMATRE; em Educação pela Università di Torino/UNITO $e$ em Mediação Intercultural e Familiar pelo Istituto SHINUI di Bergamo. Graduação em História pela USP.
} 
no final do século XIX e início do século XX até o pós-Segunda Guerra Mundial, o Brasil sempre foi um País considerado um porto de chegada de migrantes, para a partir do meio da década de 1970 se tornar um porto de saída. Atualmente o País está ressurgindo como meta da recepção de fluxos migratórios intensos.

Os migrantes estrangeiros presentes hoje no Brasil são majoritariamente provenientes da Venezuela, Bolívia, Peru, Paraguai, China e de alguns países africanos de língua portuguesa. Há, inclusive, estimativa da existência de cerca de 600 mil imigrantes ilegais hoje vivendo no Brasil. Contudo, conjuntamente à imigração para o Brasil, as emigrações brasileiras para o exterior ainda são uma realidade com destinação aos Estados Unidos, Canadá e Austrália, que, juntamente com a Europa, são as metas preferidas. Todo esse movimento migratório de idas e vindas evidência a necessidade de exames e leituras aprofundadas da mobilidade humana na atualidade, visto que ela traz especificidades que a diferenciam das mobilidades de outras épocas, sobretudo das migraçóes impulsionadas pela expansão do projeto de modernidade no ocidente.

É nesse contexto de grandes movimentos migratórios mundiais e de verificação das teorias predominantemente econômicas sobre esses processos, que se faz necessária a leitura do livro Direito de fuga ${ }^{2}$, do professor Sandro Mezzadra do Departamento de Política, Instituições e História da Universidade de Bolonha na Itália, que concentra seus trabalhos, teóricos e de ação política em temas como migração, globalização, cidadania e as possíveis relaçóes entre eles.

É certamente um dos autores atuais que contribui significativamente com seus trabalhos para a leitura sobre a questão das migraçóes, inserindo inovaçôes teóricas e metodológicas que abrem as perspectivas do fenômeno da imigração para outros discursos e práticas sociais, pois, além de professor, pesquisador acadêmico rigoroso em sua produçáo, a quem tivemos a possibilidade de conhecer recentemente, durante o primeiro semestre de 2011 frequentando um de seus cursos intitulado Le Frontiere della

2 Publicado originalmente em italiano com o titulo: Diritto di fuga. Migrazioni, cittadinanza, globalizzazione, Verona, Ombre Corte, 2006, pp. 218. 
Cittadinanza $a^{3}$, é também homem de grande atividade política que presta às suas teorias um significado de construçáo do saber e não exclusivamente de descrição.

O livro Direito de Fuga é de fundamental importância para pensarmos os movimentos migratórios da atualidade como um conjunto de práticas sociais e de subjetivação que demandam uma reflexão sobre o papel da cidadania e das fronteiras nas democracias ocidentais. É um ponto de referência imperativo para quem deseja indagar, por meio de hipóteses de pesquisas, que ultrapassem a estrita dimensão jurídico-institucional, os possíveis significados e desafios teóricos e práticos dos movimentos migratórios contemporâneos. Outro olhar sobre as migraçôes que, constituindo um fato social total pode haver uma função decisiva na construção mesma de um olhar acadêmico que não seja restrito àquele já institucionalizado. Nas palavras do próprio autor, na edição original em italiano:

Le migrazioni coinvolgono e trasformano le diverse dimensioni su cui si articolano almeno due sistemi sociali (quello di provenienza e quello di insediamento dei migranti), ma tracciano in realtà nuove linee di congiunzione e di separazioni sulle carte geografiche del pianeta che coinvolgono una molteplicità di altri spazi; trasformando i "mercato di lavoro", il discorso pubblico, le norme giuridiche e sociali, i sistemi di appartenenza, le identità, le forme di dominio di classe, i rapporti di genere - e a loro volta ne sono profondamente condizionate. (MEZZADRA, 2006, p. 196). ${ }^{4}$

Direito de Fuga é dividido em duas partes. A primeira parte é o texto em sua primeira edição de 2001, com seus quatro capítulos, acrescidos de uma introdução explicativa da nova edição, contextualizando as mudanças no mundo deste então e as repercussóes que as ideias manifestadas no livro provocaram no discurso acadêmico sobre o tema.

O primeiro capítulo, intitulado "Prólogo: O jovem Max Weber, o

3 As Fronteiras da Cidadania. (tradução nossa).

4 "As migrações que envolvem e transformam as várias dimensões sobre as quais se constroem pelo menos dois sistemas sociais (aquele de proveniência e aquele de chegada dos migrantes), mas na verdade desenhar novas linhas de junção e separação nos mapas do mundo, envolvendo uma variedade de outros espaços; transformando os "mercados de trabalho", os discursos públicos, as normas jurídicas e sociais, os sistemas de filiação, as identidades, as formas de dominação de classe, relações de gênero - e, por sua vez, estão profundamente condicionados." (MEZZADRA, 2006, p. 196, tradução nossa). 
direito de fuga dos migrantes alemães e os estômagos poloneses", é uma leitura da categoria do êxodo, da fuga em sentido mais geral e menos pretensioso, tendo como referência uma experiência histórica específica, as migraçóes dos camponeses alemães provenientes das províncias orientais da Prussia no final do século XIX, e do parecer do jovem alemão Max Weber, denotando a dimensão subjetiva dos processos migratórios com sua natureza de movimentos sociais, sem contudo negar as realidades materiais que os promovem.

No segundo capítulo, "No princípio era a forca. Migraçôes, mobilidade e história do capitalismo", dando continuidade ao primeiro capítulo e aprofundando as posiçôes de Weber, Mezzadra argumenta que a deserção se póe em uma linha de continuidade ao despotismo que comprime a mobilidade do trabalho durante o inteiro arco da história do modo de produção capitalístico, deserção subjetiva e configurada como movimento social. Desse modo, as migraçóes perdem o caráter de movimento marginal na história e são incorporadas concretamente ao modo de funcionamento de produçáo capitalista como estratégia de controle da mobilidade do trabalho.

No terceiro capítulo, "Cidadãos da fronteira e limites da cidadania", temos o exame das migraçóes à luz das ambiguidades estruturais do trabalho livre, do contrato e do salário como standart do modo de produção capitalístico e, assim, também a ideia da ambiguidade da cidadania e sua relação com os migrantes. Depois de percorrer as relaçóes existentes entre cidadania, trabalho e migraçóes, em particular no ocidente, o autor argumenta que é no contexto que a crise da cidadania, considerada anteriormente como um critério jurídico formal, tende a se transformar em um conceito denso, capaz de abarcar valores que compreendem critérios de adesão subjetiva a tal ordenamento. Por meio da análise de questóes como a exclusão e a inclusão, a diferenciação entre jus sanguinis e jus solis, integração ou desintegração, o duplo espaço dos migrantes, a questão da hibridação cultural e o problema da filiação/senso de pertencer, é que podemos observar a complexidade do tema e a ambivalência da identidade como elemento

5 Termos latinos, que se contrapõem, e que significam respectivamente direito de sangue, que reconhece a nacionalidade de um individuo de acordo com sua ascendência e, direito de solo, que reconhece a nacionalidade por nação onde nasceu. 
valioso que pode ser constituído por todos, migrantes ou não, como forma de identificação, como construção de uma identidade política.

No quarto capítulo, "Depois das colônias, o mundo", o autor avalia o quanto o mundo colonial construiu a acepção dicotômica de "nós" e "outros". O autor inicia suas reflexôes com uma explanação de todo o desenvolvimento do conceito do direito de fuga, reafirmando as tençóes subjetivas que desenham uma pluralidade de linhas de fuga que colocam em discussão qualquer concepção unívoca do "pertencer". Adverte-nos também sobre a importância dos efeitos epistemológicos do período pós-colonial moderno capitalístico com suas estratégias de segregação do mundo não europeu, com a formação de conceitos como aqueles de culturas e de "política das identidades". Chama a atenção para as noçóes de multiculturalismo, como fronteiras demarcatórias frequentemente baseadas no fundamentalismo dos brancos diferenciando aquilo que é branco como normativo e o que é não é branco caracterizado como étnico. Pondera também sobre o modo como a modernidade vem sendo pensada por meio da perspectiva dos estudos pós-coloniais que aspiram a uma renovação da concepção da história, a exemplo dos subaltern studies. Novas "fontes históricas" e novos métodos, como a genealogia de Foucault e o desconstrucionismo, fazem parte dessa possibilidade de instâncias subjetivas e híbridas.

A segunda parte do livro é composta de três diálogos sobre concordâncias, discordâncias, discussóes e polêmicas com diversos estudiosos e, também, de três textos com novas reflexóes sobre o direito de fuga.

O primeiro diálogo é com o professor e pesquisador Brett Neilson, da Universidade de Sidnei, na Austrália, que estuda formas alternativas de conceber a globalização, com particular ênfase nas dimensóes culturais dos border studies, que tomam o não lugar como um lugar préestabelecido, expondo a dramática situação dos cárceres destinados aos “ilegais" e a deserção para a Europa e a Austrália. Esse diálogo/confronto Europa-Austrália se demonstra muito profícuo no sentido de abrir novas possibilidades discursivas e metodológicas no tocante às migraçôes.

O segundo diálogo é com um grupo de estudiosos de Buenos Aires, na Argentina, emerso do ambiente estudantil na metade dos anos 1990, denominado Colectivo Situaciones, editores em castelhano do Direito de Fuga 
que desenvolveram uma longa experiência de atuação nos movimentos sociais. Os temas tratados são a subjetividade migrante, o direito de fuga, a globalização que vem de baixo, ou seja, das classes sociais populares, e, por fim, o trabalho dos migrantes. Certamente, as questóes colocadas aqui são marcadamente ideológicas por parte da esquerda latino-americana, que tende a um dogmatismo bipolar, mas Mezzadra consegue colocar a questão da exploração numa perspectiva das práticas de cidadania e de protagonismo subjetivo.

O terceiro diálogo/debate é com Etiénne Balibar, professor pesquisador na Universidade de Paris X, na França, autor muito conhecido internacionalmente, materialista histórico e politicamente militante do Partido Comunista Francês há mais de 30 anos, que defende a cidadania como um conceito diferente daquele de filiação nacional. Esse é o diálogo mais complexo e conflituoso travado em torno de questóes muito difíceis para a Europa hoje, como o islamismo e o anti-islamismo, todos os debates de radicalidade expressos depois do atentado nos Estados Unidos, em 11 de setembro 2001, os possíveis processos constituintes da cidadania na Europa, das consideradas invasóes bárbaras dos migrantes que tentam entrar nas fronteiras das ex-metrópoles, às lutas de classe e, por fim, a ubiquidade das guerras. Mezzadra defende a necessidade de instituiçóes sociais construídas a partir dos movimentos sociais resultantes de uma articulação entre a objetividade e a subjetividade de seus protagonistas.

Os três textos finais, "Fronteiras, migração, cidadania", "Capitalismo, migração e lutas sociais. Notas preliminares sobre uma teoria da autonomia da migração" e "O olhar da autonomia" podem ser considerados atualizaçóes, sínteses das principais ideias do Direito de fuga, e também uma reafirmação da importância das práticas sociais, de movimentos coletivos e comportamentos subjetivos, cruciais para pensarmos a cidadania como um espaço de conflito onde politicamente podemos nos constituir como protagonistas.

As migrações são um movimento social constituído por meio das práticas objetivas e subjetivas de cidadania dos migrantes que alteram a ideia das fronteiras da própria cidadania e o livro do professor Mezzadra nos enriquece muito com a perspectiva de uma leitura histórico-sociológica de ação política e de produção de subjetividades. 


\section{Referências}

JUSTO, J. S. Vidas errantes: políticas de mobilidade e experiências de tempo-espaço. Londrina: EDUEL, 2012.

MEZZADRA, Sandro. Direito de Fuga. Edições Unipop, 2012.

Diritto di Fuga. Migrazioni, cittadinanza, globalizzazione. Verona: Ombre Corte, 2006.

UNITED NATIONS. Trends in internacional migrant stock: the 2015 revision. New York: United Nations, 2015. Disponível em: <http://www.un.org/en/development/desa/population/ migration/data/estimates2/estimates15.shtml>. Acesso em: 10 out. 2016.

Recebido em: 20.07.2017

Aprovado em: 10.10 .2017 